\title{
Risk factors associated with poor health outcomes for children under the age of 5 with moderate acute malnutrition in rural fagita lekoma district, Awi Zone, Amhara, Ethiopia, 2016
}

\author{
W/amilak Adamu', Dube Jara2*, Mulunesh Alemayehu² and Sahai Burrowes ${ }^{3}$
}

\begin{abstract}
Background: Left untreated, moderate acute malnutrition (MAM) in children can lead to severe acute malnutrition, stunting, developmental delays, and death. Despite recent progress the prevalence of malnutrition remains high throughout Ethiopia. The ability to make accurate prognoses and develop effective treatment strategies for children with MAM is currently limited and, as result, a significant proportion of children with MAM fail to recover even with treatment. We seek to address this limitation by assessing the risk factors for poor outcomes among children under the age of 5 with MAM in a rural area of Ethiopia's Amhara Region. This region is considered relatively food secure and does not have food supplementation treatment programs.

Methods: We conducted a prospective cohort study of 404 randomly sampled children, 0-59 months old stratified by household food security status. We followed the study children for approximately 2 months, assessing their health status; and used bivariate and multivariate Cox-proportional hazard regression models to identify risk factors for poor health outcomes.

Results: Household food security was significantly associated with low recovery from MAM: 191 (60\%) of children in food-insecure and 129 (40\%) of children in food-secure households had poor health outcomes. The risk factors found to be significantly associated with poor health outcomes included the duration of exclusive breastfeeding (AHR 1.50, 95\%Cl: 1.05, 2.15), dietary diversity (AHR 1.74,95\%Cl: 1.18, 2.54), and maternal mid-upper arm circumference (AHR=1.36, $95 \% \mathrm{Cl}: 1.04,1.86)$. Children from pregnancies that were wanted but unplanned had $80 \%$ higher incidence of poor health outcomes than others, and children from pregnancies that were both unwanted and unplanned had more than double the incidence of poor health outcomes compared to their counterparts.

Conclusion: We found that without treatment, the majority of children from food insecure households and over a third of children from food secure households did not recover from MAM. Maternal factors particularly the mother's ability to plan her pregnancy were the main determinants of recovery in this study. Together these findings support arguments for targeting of nutrition support programs to vulnerable households regardless of regional food security status, and for closely integrating robust family planning, and antenatal care services with nutrition interventions.
\end{abstract}

Keywords: Food security, Malnutrition, Treatment, Recovery

\footnotetext{
* Correspondence: jaradube@gmail.com

${ }^{2}$ Department of Public Health, College of Medicine and Health Science

Debre Markos University, P.O. Box 269, Debre Markos, Ethiopia

Full list of author information is available at the end of the article
} 


\section{Background}

Worldwide, approximately $5 \%$ of children under the age of five are affected by moderate acute malnutrition (MAM) [1]. Children with MAM are at increased risk of death and are more likely to suffer delays in their physical and cognitive development than children who have not experienced malnutrition [2, 3]. Recurrent episodes of MAM in children can also lead to later childhood stunting. In turn, stunting can affect the nutritional status of subsequent generations, resulting in "intergenerational growth failure"-a cycle of poor nutrition that perpetuates itself across generations with irreversible effect [4-6]. Moderate wasting is often described as the most important risk factor for childhood illness and mortality globally, and it is directly or indirectly responsible for more than half of all deaths in children under 5 year of age $[7,8]$.

Worldwide, approximately 165 million children under 5 are stunted -56 million in Africa. Both moderate and acute malnutrition remain a significant and persistent public health problem in Ethiopia [6]. According to the 2016 Demographic and Health Survey, 38\% of children under 5 years of age were stunted; $10 \%$ had acute malnutrition; and 24\% having moderate acute malnutrition. In the Amhara Region, in which this study was conducted, almost half (46\%) of children are stunted [9].

Poor health outcomes due to MAM are not inevitable. With early adequate nutritional intervention and the prevention of infectious diseases, children with MAM can catch up their linear growth [5]. Such intervention is especially crucial in the child's first 1000 days of life, a critical period for child growth and cognitive development [10]. Action to address MAM during this window of opportunity, particularly during the complementary feeding period (between 6 to 24 months), is crucial for preventing stunting and later cognitive and developmental delays [10, 11]. However, there is still debate about the proper strategies for addressing MAM at the national-level in a cost-effective manner.

A 2016 study [12] notes that the current Ethiopian strategy for managing MAM nationally is to restrict supplementary feeding programs (SFPs) for treatment to districts (woredas) that are chronically food-insecure. In areas not considered chronically food-insecure, there are no public SFPs; instead, providers rely on existing infant and child health interventions such as vitamin A supplementation, de-worming, water treatment, improved sanitation, and nutrition counseling. Researchers have noted that while this policy is logical in terms of efficiency, it may be failing to adequately address the problem of widespread malnutrition, because aggregate, average food security at the woreda level is may mask severe food insecurity at the household level [7, 12, 13]. Household food security has been shown to be associated with developing MAM and a failure to recover from MAM [14, 15]. Children with MAM need food of sufficient energy and nutrient density in order to recover from MAM and access to such food may be limited in food-insecure households [16]. There is, therefore, concern that the current policy may be inadequate to meet this pressing health threat.

Changing national strategies to prevent and treat MAM requires a solid understanding of the factors that are related to poor health outcomes for children with MAM, particularly children not receiving treatment. Such information facilitates the development of comprehensive programs containing complementary services and allows policy makers to better assess the tradeoffs involved in not providing SFPs for children with MAM. Unfortunately, the factors related to failure to recover from MAM, particularly for children not receiving treatment, are poorly understood. There is relatively strong evidence that household food insecurity, unhealthy environmental conditions, maternal under-nutrition and inadequate care and feeding practices contribute to the development of MAM [10]. Household wealth, maternal fertility, vitamin A supplementation, good hygiene practices, safe water source, having nutritional counseling, and the child's Mid-Upper Arm Circumference (MUAC) at enrollment, have been found to be negatively associated with recovery in some studies $[12,17]$. In others, the child's age, gender, initial level of malnutrition and breastfeeding status were the important factors [18]. Household food insecurity and maternal workload have been found to be drivers of health outcomes in some studies but not in others [12]. This study wants to contribute to a better understanding of the risk factors for failure of children to recover from MAM in Ethiopia.

\section{Methods \\ Study Setting}

The study was conducted from February 2, 2016 to April 4, 2016 (the post-harvest, dry season) in the Fagita Lekoma woreda. Fagita Lekoma is one of 12 woredas in the Awi Zone, which is located in the Amhara Regional State. It is a rural woreda (20 of its 22 kebeles are rural) located $450 \mathrm{kms}$ from Ethiopia's capital, Addis Ababa [11]. We selected Fagita Lekoma because there are no SFPs in the woreda. The woreda has 6 health centers, only one of which provides outpatient care for severe acute malnutrition (SAM). The estimated population for the woreda is 156,671 ; with 36,435 households, and 21,213 children under the age of five. The five kebeles in this study had a total population of 22,682 [19].

\section{Study design and population}

This community-based prospective cohort study was conducted among children with MAM aged 0- 
59 months. Children 59 months of age or younger with MAM that lived in the randomly sampled kebeles were eligible for recruitment. We excluded children older than 59 months; whose age was not known; without MAM; with no present mother or whose mother was unable to communicate with the study team; children who had health problems or disabilities that made it difficult to collect anthropometric measurements; and children with MAM who were receiving medical treatment.

\section{Sample size and sampling techniques}

Because food security has been shown to be an important factor for predicting poor health outcomes in children with MAM we selected it as an "exposure" variable for sample size calculation and for the stratification of our Kaplan-Meier survival plots [12]. Households were categorized as food-secure and food-insecure based on Household Food Insecurity Access Scale (HFIAS) results that were from previous study [12]. We calculated our sample size using the double population proportion formula. Our assumptions were as follows: $37.78 \%$ children with MAM in food-secure households would have poor health outcomes [12] for an adjusted hazard ratio (AHR) of 1.39 for poor health outcome among food-secure compared to food insecure households [12]. We assumed a 95\% two-sided confidence interval (CI), a statistical power of $80 \%$, and a one-toone allocation ratio of food-secure to food-insecure. Based on these assumptions, using EPI INFO 7 [20], we calculated a sample size 384. Allowing for an additional $5 \%$ non-response rate, the total sample size was 404 (202 for food-secure households and 202 for foodinsecure households).

We randomly selected 5 kebeles from Fagita Lekoma's 20 rural kebeles $(25 \%)$ using a simple random sample lottery method. We then visited all households in the selected kebeles and screened all children aged 059 months $(n=2995)$ for their nutritional status. We used the conventional definition of MAM: having a weight-for-height (WFH) below the WHO median child growth standards (the child growth with Z-scores between -3SD to -2SD).

All children were assessed for WFH using WHO Anthro version 3.2.2 software and those with MAM were identified and registered. At this time we also categorized households as food insecure and food secure. We found 414 children with MAM (202 from food-secure and 212 from food insecure households). We retained all 202 children from food-secure households. We randomly selected 202 children from the remaining 212 food-insecure households using a lottery method. When there was more than one child with MAM in a household, we selected one of them using lottery method. The selected children were enrolled in the study and followed for two months.

\section{Study variables and measurement}

Our outcome variable was whether, by the two-month follow up visit, a child had progressed to severe acute malnutrition (SAM); had not recovered from MAM, or had died. Children with any of these outcomes were categorized as having "poor health outcomes".

We categorize children as having MAM, if at the second follow up visit, they had a weight-for-height/length (WFH/L) between -3 and -2 Z-scores (-3SD to -2SD of the WHO median value), or WFH/L at $70-80 \%$ of the $\mathrm{Na}$ tional Center for Health Statistics (NCHS), or had a MUAC measurement that was $>=11.5 \mathrm{~cm}<12.5 \mathrm{~cm}$, without edema. Children whose MAM status did not change by the 2-month follow up period were categorized as not recovering. We categorized children as having SAM if, at the first or second follow-up visit, they had WFH/L below $-3 \mathrm{SD}$ of the WHO median value and/or (WFH/L) below $70 \%$ of the NCHS median value and/or MUAC $<11.5 \mathrm{~cm}$, with or without edema. Children were categorized as recovering if, at first and/or second follow up visit, they had WFH/L Z-scores $>=-2 \mathrm{SD}$ of the WHO median value and/or WFH/L $>=80 \%$ of the NCHS, and/ or MUAC $>=12.5 \mathrm{~cm}$ ) with no edema.

\section{Data collection methods}

We collected data using a cross-sectional, structured, interviewer-administered questionnaire containing closed-ended questions and by taking anthropometric measurements of children and their mothers during home visits.

Our study began with the development of a project survey and the recruitment of project staff. Our survey was developed from standard, validated, Englishlanguage instruments that were translated to into Amharic. We recruited 2 health officers to supervise data collection, and 10 health extension workers and 3 nurses to act as data collectors. All spoke Amharic, the local language. We then conducted one-day training on how to collect the data for the data collectors and supervisors and then pre-tested the questionnaire in a kebele that was adjacent to our study kebeles, with 20 households ( $5 \%$ of our sample size).

The study had three data collection points: we collected baseline survey and anthropometric data during community-based nutritional screening for all children 0-59 months of age in our 5 sampled kebeles. We used the HFIAS to measure food security for stratifying the sample [21]. This tool is the current standard for assessing household-level food security and has been validated for use in Ethiopia [22]. Households that were enrolled in the study were visited once monthly for 
2 months, during which mothers were asked follow up survey questions and anthropometric measurements of the study children were taken.

The survey contained questions on socio-economic factors, demographic risk factors, child characteristics, child-care practices, maternal characteristics, and environmental risk factors. We recorded the child's vaccination status by reviewing immunization cards when these were available, or by using the mother's recall. We checked bacille Calmette-Guerin vaccination by observing whether there was scar on the child's arm.

We used procedures stipulated by the WHO to take anthropometric measurements [23]. Before measuring children we established their age, using a local event to establish the child's birth period. Mothers were asked whether the child was born before or after certain major events until a fairly accurate age was pinpointed. If we were not able to determine the child's age accurately, the next child in the household was recruited. We measured body length of children age up to 23 months (or those who were older but too ill to stand) in the recumbent position, without shoes, reading the length to the nearest $0.1 \mathrm{~cm}$ or $1 \mathrm{~mm}$ using a horizontal wooden length measuring board/sliding board. We measured MUAC for both the study children and their mothers. MUAC was measured on left mid upper arm half way between the olecranon process and acromion process using a nonstretchable strap, to the nearest $1 \mathrm{~mm}$.

\section{Quality control measures}

We checked the calibration of the measurement scale by weighing a $2-\mathrm{kg}$ stone after each child measurement and after moving the scale from one household to another. Then the scale indicators were checked against a zero reading before and after weighing every child and mother. Only one observer was used for each subject. Mothers and children were required to wear only light clothing in order not to skew the weight results. The project principal investigator reviewed collected data on a daily basis, and returned records with possible errors to the data collectors for correction.

\section{Data processing and analysis}

The collected data were checked for completeness, consistency and entered using EPI-data software; then the data were exported to SPSS version 20 for analysis [24]. Descriptive analysis such as Kaplan-Meier survival curves and log-rank test statistics were used to describe important variables of the study and compare the outcome variables. A Cox-regression model was fitted to identify risk factors for poor health outcomes of MAM. All predictors that were associated with the outcome variable in bivariate analysis at $p$-values of 0.20 or lower were included in our multivariate Cox-regression models. Crude and adjusted hazard risks with their corresponding 95\% confidence intervals were computed. Variables with p-values $<0.05$ were considered statistically significant risk factors in this study.

\section{Results}

A total of 202 children with MAM in food-secure and 202 in food-insecure households were enrolled in the study with no loss to follow-up, for an overall response rate of $100 \%$.

\section{Socio-demographic and economic characteristics}

The sample was homogenous in terms of religion and ethnicity (100\% Awi ethnicity and Ethiopian Orthodox). Most households were male-headed: 182 (90\%) in-food secure, and 180 (89.1\%) in food-insecure households. Approximately two-thirds of households had 5 members or more: 130 (64.35\%) in food secure, and 138 (68.31\%) in food-insecure households. Approximately $40 \%$ of sample fathers and $64 \%$ of mothers were illiterate. Slightly less than half (46\%) of mothers report that their husbands were in charge of decision-making regarding the use of household money. Almost all households earned less than 750 Ethiopian birr per month (approximately 32 US dollars) (see Table 1).

\section{Child characteristics}

Approximately half of the study children were female. The vast majority had been full term births (81.69\%), that occurring within a 24-48 month birth interval (52.72\%). The plurality (47.28\%) were between the age of 12-23 (See Table 2).

\section{Child care characteristics}

We found high rates of exclusive breastfeeding in children from food-insecure households (83.47\%) but more modest rates in among households with higher food security (57.14\%). Roughly $80 \%$ had been given breast milk immediately after birth. More than half of the children $(55.44 \%$ and $59.9 \%$ in food-secure and insecure households respectively) were being breastfed at the time of data collection.

A larger proportion of children in food-secure households had not been given pre-lactation feeding than in food-secure households ( $86.16 \%$ vs. $82.67 \%)$. The most common pre-lactation foods were water, butter, and milk. At the time of the survey, $88.09 \%$ of mothers in the food-secure households and $73.59 \%$ from foodinsecure households reported having eaten from less than 4 food groups within the last $24 \mathrm{~h}$ (see Table 3 ).

\section{Maternal characteristics}

Many mother in the study were either malnourished or highly vulnerable to malnutrition. The majority of 
Table 1 Socio-demographic and economic household characteristics in Fagita District, Awi Zone, Amhara, Ethiopia, 2016

\begin{tabular}{|c|c|c|c|c|c|}
\hline \multirow{3}{*}{$\begin{array}{l}\text { Variables } \\
\text { Sex HH head }\end{array}$} & \multirow{3}{*}{$\begin{array}{l}\text { Description } \\
\text { Female }\end{array}$} & \multicolumn{4}{|c|}{ Moderate Acute Malnutrition } \\
\hline & & \multicolumn{2}{|c|}{ Food-Secure Households } & \multicolumn{2}{|c|}{ Food-Insecure Households } \\
\hline & & 20 & $9.90 \%$ & 22 & $10.89 \%$ \\
\hline & Male & 182 & $90.0 \%$ & 180 & $89.1 \%$ \\
\hline \multirow[t]{4}{*}{ Age of male HH head } & $15-39$ & 27 & $13.36 \%$ & 27 & $13.36 \%$ \\
\hline & $30-39$ & 72 & $35.64 \%$ & 64 & $31.68 \%$ \\
\hline & $40-49$ & 75 & $37.12 \%$ & 82 & $40.59 \%$ \\
\hline & 50andabove & 8 & $3.90 \%$ & 7 & $3.46 \%$ \\
\hline \multirow[t]{3}{*}{ Marital Status of HH Head } & Married & 182 & $90.09 \%$ & 180 & $89.1 \%$ \\
\hline & Divorced & 12 & $5.94 \%$ & 16 & $7.92 \%$ \\
\hline & Widowed & 8 & $3.96 \%$ & 6 & $2.97 \%$ \\
\hline \multirow[t]{2}{*}{ No. of person in household } & $<5$ & 72 & $35.64 \%$ & 64 & $31.68 \%$ \\
\hline & 5 and above & 130 & $64.35 \%$ & 138 & $68.31 \%$ \\
\hline \multirow[t]{2}{*}{ Father's Educational Status } & Can't Read \&write & 91 & $45.04 \%$ & 80 & $39.6 \%$ \\
\hline & Can Read \&Write and above & 91 & $45.04 \%$ & 100 & $49.5 \%$ \\
\hline \multirow[t]{2}{*}{ Maternal Educational Status } & Can't read \&write & 137 & $67.8 \%$ & 121 & $59.9 \%$ \\
\hline & Can Read \&Write and above & 65 & $32.17 \%$ & 81 & $40.09 \%$ \\
\hline Maternal Occupational Status & Farmer & 200 & $99 \%$ & 201 & $99.5 \%$ \\
\hline \multirow[t]{4}{*}{ Who Decides Money Use } & Mainly spouse & 20 & $9.9 \%$ & 24 & $11.880 \%$ \\
\hline & Mainly husband & 94 & $46.53 \%$ & 98 & $48.53 \%$ \\
\hline & Both & 66 & $32.67 \%$ & 56 & $27.72 \%$ \\
\hline & Only husbanded & 22 & $10.89 \%$ & 24 & $11.88 \%$ \\
\hline \multirow[t]{2}{*}{ Monthly Income } & $<750$ & 192 & $95.05 \%$ & 195 & $96.50 \%$ \\
\hline & $750+$ & 10 & $4.95 \%$ & 7 & $3.50 \%$ \\
\hline
\end{tabular}

Table 2 Child characteristics in Rural Fagita District, Awi Zone, Amhara, Ethiopia, 2016

\begin{tabular}{|c|c|c|c|c|c|}
\hline \multirow{3}{*}{$\begin{array}{l}\text { Variables } \\
\text { Child's sex }\end{array}$} & \multirow{3}{*}{$\begin{array}{l}\text { Description } \\
\text { Female }\end{array}$} & \multicolumn{4}{|c|}{ Moderate acute malnutrition } \\
\hline & & \multicolumn{2}{|c|}{ Food-Insecure Households } & \multicolumn{2}{|c|}{ Food-Insecure Households } \\
\hline & & 101 & $50.0 \%$ & 111 & $54.95 \%$ \\
\hline & Male & 101 & $50.0 \%$ & 91 & $45.04 \%$ \\
\hline \multirow[t]{5}{*}{ Child's age } & $0-11$ & 29 & $14.35 \%$ & 31 & $15.34 \%$ \\
\hline & $12-23$ & 99 & $49.00 \%$ & 102 & $50.45 \%$ \\
\hline & $24-35$ & 50 & $24.75 \%$ & 44 & $21.78 \%$ \\
\hline & $36-47$ & 18 & $8.90 \%$ & 18 & $8.90 \%$ \\
\hline & $48-59$ & 6 & $2.90 \%$ & 7 & $3.40 \%$ \\
\hline \multirow[t]{2}{*}{ Birth interval } & 0-23 months & 95 & $47.02 \%$ & 85 & $42.07 \%$ \\
\hline & $24+$ months & 107 & $52.97 \%$ & 117 & $57.92 \%$ \\
\hline \multirow[t]{2}{*}{ Gestational age } & $<9$ month & 28 & $13.86 \%$ & 46 & $22.77 \%$ \\
\hline & $9+$ month & 174 & $86.13 \%$ & 156 & $77.22 \%$ \\
\hline \multirow[t]{2}{*}{ IIIness in the last 2 weeks } & 149 & $73.76 \%$ & 147 & $72.77 \%$ & \\
\hline & 53 & $26.23 \%$ & 55 & $27.22 \%$ & \\
\hline \multirow[t]{4}{*}{ Frequency of health problems } & Fever & 9 & $16.98 \%$ & 5 & $9.00 \%$ \\
\hline & Cough & 6 & $11.32 \%$ & 5 & $9.00 \%$ \\
\hline & Fever \& cough & 13 & $24.52 \%$ & 25 & $45.45 \%$ \\
\hline & Vomiting \&diarrhea & 25 & $47.16 \%$ & 20 & $36.36 \%$ \\
\hline
\end{tabular}


Table 3 Child caring characteristics in Rural Fagita District, Awi Zone, Amhara, Ethiopia, 2016

\begin{tabular}{|c|c|c|c|c|c|}
\hline \multirow{3}{*}{$\begin{array}{l}\text { Variables } \\
\text { Breast fed }\end{array}$} & \multirow{3}{*}{$\begin{array}{l}\text { Description } \\
\text { No }\end{array}$} & \multicolumn{4}{|c|}{ Moderate Acute Malnutrition } \\
\hline & & \multicolumn{2}{|c|}{$\begin{array}{l}\text { Food-Secure } \\
\text { Households }\end{array}$} & \multicolumn{2}{|c|}{$\begin{array}{l}\text { Food-Insecure } \\
\text { Households }\end{array}$} \\
\hline & & 90 & $44.55 \%$ & 81 & $40.09 \%$ \\
\hline & Yes & 112 & $55.44 \%$ & 121 & $59.9 \%$ \\
\hline \multirow[t]{2}{*}{ Time to initiate breast feeding } & Immediately & 92 & $82.14 \%$ & 97 & $80.16 \%$ \\
\hline & $>=1 \mathrm{Hr}$ of Delivery & 20 & $17.85 \%$ & 24 & $19.83 \%$ \\
\hline \multirow[t]{2}{*}{ Frequency of breast feed in $24 \mathrm{hrs}$} & $<8$ time/day & 21 & $18.75 \%$ & 23 & $19.00 \%$ \\
\hline & 8-12 time/day \& above & 91 & $81.25 \%$ & 98 & $80.99 \%$ \\
\hline \multirow[t]{2}{*}{ Exclusively breast feed } & $<6$ month & 48 & $42.85 \%$ & 20 & $16.52 \%$ \\
\hline & $>=6$ month & 64 & 57.14 & 101 & $83.47 \%$ \\
\hline \multirow[t]{2}{*}{ Pre-lactation food/fluid } & No & 174 & $86.13 \%$ & 167 & $82.67 \%$ \\
\hline & Yes & 28 & $13.86 \%$ & 35 & $17.32 \%$ \\
\hline \multirow[t]{2}{*}{ Material used to feed the child } & Cup & 27 & $96.42 \%$ & 30 & $85.74 \%$ \\
\hline & Bottle & 1 & $3.57 \%$ & 5 & $14.28 \%$ \\
\hline \multirow[t]{2}{*}{ Who is in charge of the baby's Feeding } & Mother & 199 & $98.51 \%$ & 198 & $98.01 \%$ \\
\hline & Sister & 3 & $1.48 \%$ & 3 & $1.48 \%$ \\
\hline \multirow[t]{2}{*}{ Sickness in the last 2 weeks } & No & 191 & $94.55 \%$ & 190 & $94.05 \%$ \\
\hline & Yes & 11 & $5.44 \%$ & 12 & $5.94 \%$ \\
\hline \multirow[t]{2}{*}{ Breast feeding until 1 year(6-23 month) } & No & 1 & $0.78 \%$ & 1 & $0.78 \%$ \\
\hline & Yes & 126 & $99.2 \%$ & 127 & $99.21 \%$ \\
\hline \multirow[t]{3}{*}{ Time to start complementary feeding(6-23month) } & 1-5months & 24 & $19.04 \%$ & 29 & $22.83 \%$ \\
\hline & 6 months & 89 & $68.99 \%$ & 84 & $66.14 \%$ \\
\hline & 7-12months & 14 & $11.11 \%$ & 14 & $11.02 \%$ \\
\hline \multirow[t]{2}{*}{ Took soft thick (semi solid) porridge (6-8 months) } & No & 42 & $10.4 \%$ & 51 & $12.6 \%$ \\
\hline & Yes & 8 & $2.0 \%$ & 9 & $2.2 \%$ \\
\hline \multirow[t]{3}{*}{ Frequency the child take semi-solid porridge(6-8 month) } & 1-2 time/day & 3 & $37.5 \%$ & 4 & $44.44 \%$ \\
\hline & 2-3 time/day & 4 & $50.00 \%$ & 4 & $44.44 \%$ \\
\hline & 3-4 time/day & 1 & $12.5 \%$ & 1 & $11.11 \%$ \\
\hline \multirow[t]{2}{*}{ Took soft thick (semi solid) porridge (9-11 months) } & No & 41 & $75.92 \%$ & 52 & $81.25 \%$ \\
\hline & Yes & 13 & $24.07 \%$ & 12 & $18.75 \%$ \\
\hline \multirow[t]{2}{*}{ Family food consumption } & No & 39 & $34.51 \%$ & 39 & $33.33 \%$ \\
\hline & Yes & 74 & $65.48 \%$ & 78 & $66.66 \%$ \\
\hline \multirow[t]{3}{*}{ Frequency of family food } & 1-2 time/day & 8 & $10.81 \%$ & 4 & $51.28 \%$ \\
\hline & 2-3 time/day & 64 & $86.48 \%$ & 71 & $91 \%$ \\
\hline & 3-4 time/day & 2 & $2.70 \%$ & 3 & $3.84 \%$ \\
\hline \multirow[t]{5}{*}{ The number of MDD intake } & Legumes \& Nut & 4 & $3.10 \%$ & 6 & $4.68 \%$ \\
\hline & Diary Products & 79 & $62.20 \%$ & 86 & $67.18 \%$ \\
\hline & Grain, rut, tuber, diary product, Legume \& Nuts & 38 & $29.92 \%$ & 26 & $20.31 \%$ \\
\hline & $<4$ food groups & 111 & $88.09 \%$ & 101 & $79.52 \%$ \\
\hline & $4+$ food groups & 15 & $11.91 \%$ & 31 & $20.48 \%$ \\
\hline \multirow[t]{2}{*}{ MDD in 24 hours stop breast milk } & No & 113 & $88.97 \%$ & 118 & $92.18 \%$ \\
\hline & Yes & 14 & $11.02 \%$ & 10 & $7.81 \%$ \\
\hline \multirow[t]{2}{*}{ Immunized } & No & 0 & $0 \%$ & 1 & $0.79 \%$ \\
\hline & Yes & 127 & $100 \%$ & 127 & $99.21 \%$ \\
\hline
\end{tabular}


Table 3 Child caring characteristics in Rural Fagita District, Awi Zone, Amhara, Ethiopia, 2016 (Continued)

\begin{tabular}{|c|c|c|c|c|c|}
\hline \multirow{3}{*}{$\begin{array}{l}\text { Variables } \\
\text { Vitamin A supplementation }\end{array}$} & \multirow{3}{*}{$\begin{array}{l}\text { Description } \\
\text { No }\end{array}$} & \multicolumn{4}{|c|}{ Moderate Acute Malnutrition } \\
\hline & & \multicolumn{2}{|c|}{$\begin{array}{l}\text { Food-Secure } \\
\text { Households }\end{array}$} & \multicolumn{2}{|c|}{$\begin{array}{l}\text { Food-Insecure } \\
\text { Households }\end{array}$} \\
\hline & & 26 & $20.47 \%$ & 26 & $20.31 \%$ \\
\hline & Yes & 101 & $79.52 \%$ & 102 & $79.69 \%$ \\
\hline \multirow[t]{4}{*}{ Vaccines received } & Only Penta 1 and $2 \mathrm{~K}$ & 3 & $2.3 \%$ & 4 & $3.12 \%$ \\
\hline & Fully & 107 & $84.25 \%$ & 110 & $85.93 \%$ \\
\hline & BCG, penta1-penta3 & 12 & $11.81 \%$ & 6 & $4.68 \%$ \\
\hline & Not Sure & 5 & $3.90 \%$ & 4 & $3.12 \%$ \\
\hline
\end{tabular}

mothers were 30-39 years old. A significant proportion had a chronic energy deficiency (30\% in food-secure households and $43 \%$ in food-insecure households). According to the MUAC measurements, almost half of the mothers $(49 \%)$ from food-secure households and more than two-thirds (70\%) of mothers from food insecure household were acutely malnourished. Almost 70\% of mothers had experienced 2 to 5 pregnancies. Most had not been able to eat extra meals during these pregnancies or during lactation. We found large differences between food-secure and insecure mothers in whether the child enrolled in the study had come from a planned and/or wanted pregnancy. While a large majority $(73 \%)$ of pregnancies in food-secure households had been wanted and planned, only 56\% of pregnancies in food-insecure households were wanted and planned. This difference was statistically significant (see Table 4).

Table 4 Maternal characteristics in Rural Fagita District, Awi Zone, Amhara, Ethiopia, 2016

\begin{tabular}{|c|c|c|c|c|c|}
\hline \multirow{3}{*}{$\begin{array}{l}\text { Variables } \\
\text { Mother's age }\end{array}$} & \multirow{3}{*}{$\begin{array}{l}\text { Description } \\
15-29\end{array}$} & \multicolumn{4}{|c|}{ Moderate Acute Malnutrition } \\
\hline & & \multicolumn{2}{|c|}{ Food-Secure Households } & \multicolumn{2}{|c|}{ Food-Insecure Households } \\
\hline & & 50 & $24.75 \%$ & 45 & $22.27 \%$ \\
\hline & $30-39$ & 120 & $59.40 \%$ & 120 & $59.40 \%$ \\
\hline & $40-49$ & 32 & $15.84 \%$ & 37 & $18.31 \%$ \\
\hline \multirow[t]{2}{*}{ BMlin kg/m2 } & $<18.5 \mathrm{~kg} / \mathrm{m} 2$ (CED) & 60 & $29.70 \%$ & 87 & $43.06 \%$ \\
\hline & $18.5+\mathrm{kg} / \mathrm{m} 2(\mathrm{NM})$ & 142 & $70.29 \%$ & 115 & $56.93 \%$ \\
\hline \multirow[t]{2}{*}{ MUAC in centimeter } & $<23 \mathrm{~cm}$ & 99 & $49.00 \%$ & 141 & $69.8 \%$ \\
\hline & $>=23 \mathrm{~cm}$ & 103 & $51.00 \%$ & 61 & $30.2 \%$ \\
\hline \multirow[t]{3}{*}{ Gravidity } & 1 & 28 & $13.86 \%$ & 25 & $12.37 \%$ \\
\hline & $2-5$ & 136 & $67.32 \%$ & 138 & $68.31 \%$ \\
\hline & $>5$ & 38 & $18.81 \%$ & 39 & $19.30 \%$ \\
\hline \multirow[t]{3}{*}{ Parity } & 1 & 28 & $13.86 \%$ & 25 & $12.37 \%$ \\
\hline & $2-5$ & 137 & $67.82 \%$ & 139 & $68.81 \%$ \\
\hline & $>5$ & 37 & $18.31 \%$ & 38 & $18.81 \%$ \\
\hline \multirow[t]{2}{*}{ Extra meal during pregnancy } & No & 129 & $63.86 \%$ & 138 & $68.31 \%$ \\
\hline & Yes & 73 & $36.13 \%$ & 64 & $31.68 \%$ \\
\hline \multirow[t]{2}{*}{ Number of extra meals during pregnancy } & $<2$ time/day & 44 & $60.27 \%$ & 41 & $64.06 \%$ \\
\hline & $>=2$ time/day & 29 & $39.72 \%$ & 23 & $35.93 \%$ \\
\hline \multirow[t]{2}{*}{ Extra meals during lactation } & No & 137 & $67.82 \%$ & 145 & $71.78 \%$ \\
\hline & Yes & 65 & $32.17 \%$ & 57 & $28.21 \%$ \\
\hline \multirow[t]{2}{*}{ Number of extra meals during pregnancy } & $<2$ time/day & 45 & $69.23 \%$ & 35 & $61.4 \%$ \\
\hline & $>=2$ time/day & 20 & $30.76 \%$ & 22 & $38.59 \%$ \\
\hline \multirow[t]{3}{*}{ Pregnancy type } & Wanted \& planned & 148 & $73.26 \%$ & 113 & $55.94 \%$ \\
\hline & Wanted \& unplanned & 33 & $16.33 \%$ & 61 & $30.19 \%$ \\
\hline & Unwanted \& unplanned & 21 & $10.39 \%$ & 28 & $13.86 \%$ \\
\hline
\end{tabular}




\section{Health Outcomes}

Children enrolled in the study were followed for 64 days. The minimum and maximum follow up days were 31 and 64 days, respectively. By the last follow up visit, 320 (79\%) had poor health outcomes: $191(60 \%)$ from food-insecure and 129 (40\%) from food-secure households. As follow up time increased, the hazard of the children developing poor health outcomes was higher for those who had been exclusively breastfed for less than 6 months comparing with those who had not (please see Fig. 1).

\section{Median recovery times}

The median recovery time was 62 days for children from food secure households (95\% CI 61.65-62.35) and 63 days for children from food insecure households (95\% CI 62.78-63.22). The overall median recovery time was 63 days (95\%CI 62.83-63.17) (see Table 5).

Recovery time was one day longer for children whose mothers had low baseline MUAC measurements (63 days for mothers with MUAC $<23 \mathrm{~cm}(95 \%$ CI 62.83, 63.17) versus 62 days for mothers with MUAC $>=23 \mathrm{~cm}(95 \%$ CI 61.62, 62.38). Children with well-nourished mothers from food-secure households had the fastest recovery. Their median recovery time was 61 days $(95 \%$ CI 60.65 , 61.35) compared to 63 days ( $95 \%$ CI $62.44,63.56)$ for children whose mothers were well-nourished from foodinsecure households (see Table 6).

\section{Risk factors for poor health outcomes due to MAM}

In order to identify variables for our multivariate regression models we run bivariate Cox regressions containing variables that had been shown to be risk factors for poor health outcomes in past studies. We retained all variables that were found to be statistically significant at the $20 \%$ level or lower. We then run a multivariate Cox regression model containing all of these variables and retained the variables that were associated with poor health outcomes in children at the $5 \%$ level of significance. These four variables were: whether the mother had breastfed the child exclusively, the diversity of the child's diet, maternal malnutrition, and whether the mother's pregnancy had been planned and/or wanted (see Table 7).

The risk of having poor health outcomes among children who had been exclusively breastfed for less than 6 months were $50 \%$ times higher than among children who had exclusively breastfed for 6 months or more $(\mathrm{AHR}=1.50,95 \%$ CI: $1.05,2.15)$. Children with MAM had $74 \%$ higher risk of having poor health outcomes if they had eaten less than 4 food groups in the last $24 \mathrm{~h}$ compared with children whose diet was more diverse $(\mathrm{AHR}=1.74,95 \% \mathrm{CI}: 1.184,2.54)$. Maternal nutritional

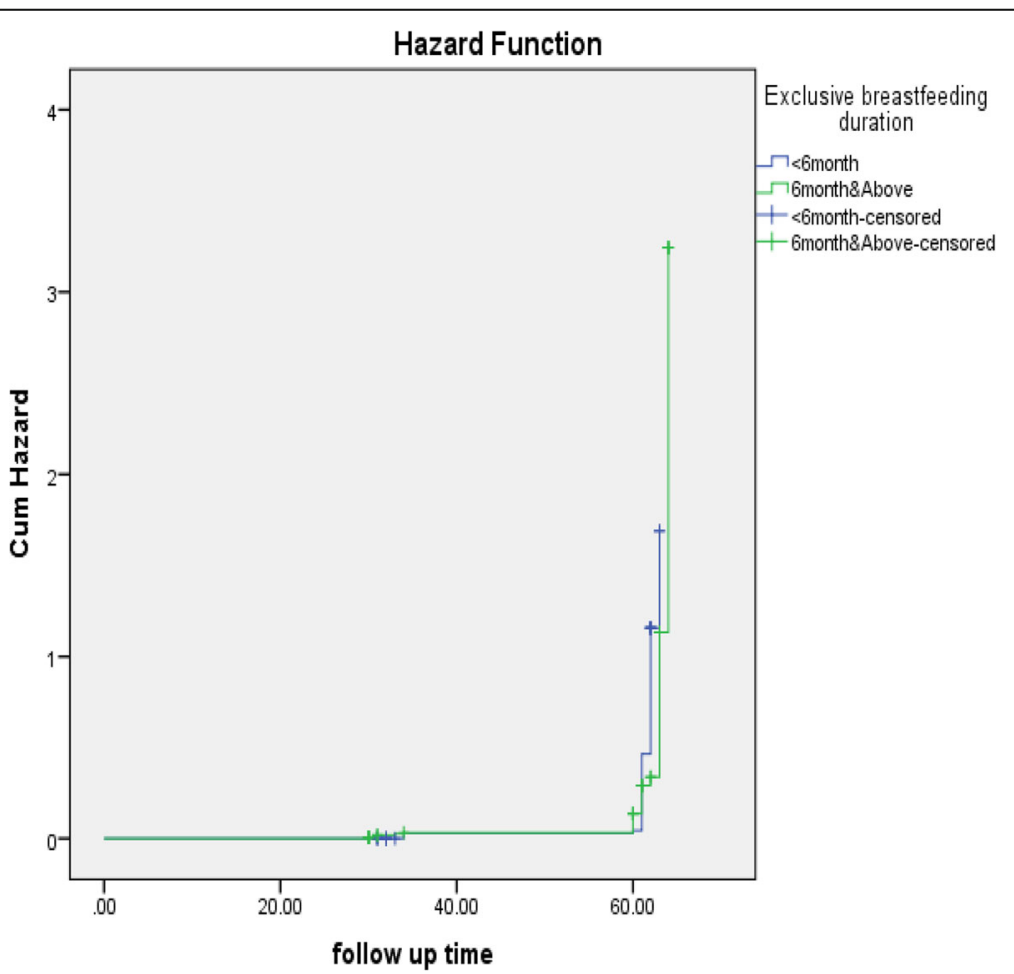

Fig. 1 Kaplan-meier hazard estimation of moderate acute malnutrition children by duration of exclusive breastfeeding, in Fagita District, Awi Zone, Amhara, Ethiopia, 2016 
Table 5 Median recovery time for children with moderate acute malnutrition in Rural Fagita District, Awi Zone, Amhara, Ethiopia, 2016

\begin{tabular}{lllllll}
\hline Food security Status & Mean & Std. Error & $95 \% \mathrm{Cl}$ & Median & Std. Error & $95 \% \mathrm{Cl}$ \\
\hline Food secure & 62.29 & 0.097 & $(62.10,62.48)$ & 62.0 & 0.178 & $(61.65,62.35)$ \\
Food insecure & 61.67 & 0.432 & $(60.82,62.51)$ & 63.0 & 0.111 & $(62.78,63.22)$ \\
Overall & 61.98 & 0.225 & $(61.54,62.42)$ & 63.0 & 0.087 & $(62.83,63.17)$ \\
\hline
\end{tabular}

status was significantly associated with poor health outcomes. Children whose mothers had MUAC measurements less than $23 \mathrm{~cm}$ had $36 \%$ higher risk of having poor health outcomes than children whose mothers had measurement that were $>=23 \mathrm{~cm} \quad(\mathrm{AHR}=1.36,95 \% \mathrm{CI}$ : $1.04,1.86)$. We also found a surprisingly strong association between whether a pregnancy was planned and/or wanted and the risk of poor health outcomes. Poor health outcomes were $80 \%$ higher among children born of unplanned pregnancies that were wanted compared children from wanted and planned pregnancies $(\mathrm{AHR}=1.80,95 \%$ CI: $1.27,2.26)$. And the risk of poor health outcomes was $119 \%$ higher among children born of pregnancies that were both unwanted and unplanned $(\mathrm{AHR}=2.19,95 \% \mathrm{CI}$ : $1.44,3.31)$.

\section{Discussion}

This study set out to explore the risk factors associated with poor health outcomes in children with MAM in a food-secure region of Ethiopia with little access to supplemental feeding programs. We found that without treatment, the vast majority of children (79\%) did not recover from MAM and that the proportion of children who failed to recover was significant even in food-secure households (approximately 40\%). This high level of nonrecovery is concerning particularly because most of the children in our study were in the critical, first 1000 days of life. Studies have found that children in this vulnerable age range ( $0-23$ months) are relatively more prone to moderate wasting, which is often exacerbated by bouts of diarrhea and respiratory illness, deteriorating into more severe illness [10].

Two of the risk factors found in our study were consistent with those found previously, namely, maternal nutritional status and the diversity of the child's diet
[12]. However, several of our findings were unusual. Many of the factors found to be associated with the development of, or the recovery from, moderate acute malnutrition in other studies were not found to be significant factors in risk of non-recovery in our study. These include the child's age, household wealth [25], maternal education [11], household income [11], drinking water source, sanitation (e.g., hand washing practices, appropriate waste disposal and latrine availability), household size [12], having received vitamin A supplementation or de-worming interventions [26] . This discrepancy may be due to the fact that our study took place during the post-harvest season when relative abundance of food might have mitigated or washed out the impact of other factors. The positive impact of high rates of exclusive breastfeeding that we observed in this study may have also played a similar role.

However, the rates of poor health outcomes for children with MAM observed in this study were quite high, and indeed much higher than that observed in previous Ethiopian research. For example, a similar study, recently conducted in Jimma found that roughly $62 \%$ of children with MAM either deteriorated or remained with MAM compared to our $79 \%$ rate [12]. Their lower rates may be due to differences between our sample in the age ranges of children (our sample was considerably younger than these previous studies) and the fact that the follow up period in the Jimma study was longer than ours, which gave children a more time to recover. There may have also been differences in our samples the duration of exclusive breastfeeding and the proportion of pregnancies that were wanted and planned. .

Indeed, the strength of association between poor health outcomes and whether a pregnancy was planned and/or wanted was one of the surprising findings of this

Table 6 Median recovery time for children with moderate acute malnutrition by Maternal MUAC in Rural Fagita District, Awi Zone, Amhara, Ethiopia, 2016

\begin{tabular}{llllllll}
\hline MUAC in centimeter & Food security Status & Mean & Std. Error & $95 \% \mathrm{Cl}$ & Median & Std. Error & $95 \% \mathrm{Cl}$ \\
\hline$<23 \mathrm{~cm}$ & Food secure & 62.78 & 0.114 & $(62.56,63.00)$ & 63.0 & 0.130 & $(62.75,63.26)$ \\
& Food insecure & 61.24 & 0.661 & $(59.95,62.54)$ & 63.0 & 0.119 & $(62.77,63.23)$ \\
& Overall & 61.90 & 0.384 & $(61.15,62.65)$ & 63.0 & 0.088 & $(62.83,63.17)$ \\
$>=23 \mathrm{~cm}$ & Food secure & 61.78 & 0.141 & $(61.50,62.06)$ & 61.0 & 0.181 & $(60.65,61.35)$ \\
& Food insecure & 62.45 & 0.167 & $(62.12,62.77)$ & 63.0 & 0.285 & $(62.44,63.56)$ \\
& Overall & 62.08 & 0.111 & $(61.86,62.30)$ & 62.0 & 0.194 & $(61.62,62.38)$ \\
\hline
\end{tabular}


Table 7 Risk factors for poor health outcomes of moderate acute malnutrition in multivariate cox regression in Rural Fagita District, Awi Zone, Amhara, Ethiopia, 2016

\begin{tabular}{|c|c|c|c|c|c|}
\hline \multirow[t]{2}{*}{ Variable } & \multicolumn{2}{|c|}{ Moderate Acute Malnutrition } & \multirow[t]{2}{*}{$\mathrm{CHR}$ at $95 \% \mathrm{Cl}$} & \multirow[t]{2}{*}{ AHR at $95 \% \mathrm{Cl}$} & \multirow{2}{*}{$\begin{array}{l}p- \\
\text { Value }\end{array}$} \\
\hline & Food-Secure Households & Food-Insecure Households & & & \\
\hline \multicolumn{6}{|l|}{ Exclusive breast feeding } \\
\hline$<6$ month & $48(42.85 \%)$ & $20(16.52 \%)$ & $1.89(1.36,2.62)$ & $1.50(1.05,2.15)$ & 0.027 \\
\hline$>=6$ month & $64(57.14 \%)$ & $101(83.47)$ & 1 & 1 & \\
\hline \multicolumn{6}{|l|}{ Dietary diversity } \\
\hline$<4$ food groups & 111 (88.09\%) & $101(75.59 \%)$ & $1.67(1.19,2.37)$ & $1.74(1.184,2.54)$ & 0.005 \\
\hline$>=4$ food groups & $15(11.90 \%)$ & $31(24.40 \%)$ & 1 & 1 & \\
\hline \multicolumn{6}{|l|}{ Maternal MUAC } \\
\hline$<23 \mathrm{~cm}$ & $99(49.00 \%)$ & $141(69.8 \%)$ & $1.45(1.14,1.82)$ & $1.36(1.05,1.86)$ & 0.044 \\
\hline$>=23 \mathrm{~cm}$ & $103(51 \%)$ & $61(30.19 \%)$ & 1 & 1 & \\
\hline \multicolumn{6}{|l|}{ Pregnancy type } \\
\hline Wanted \& planned & $148(73.26 \%)$ & $113(55.94 \%)$ & 1 & 1 & \\
\hline Wanted \& unplanned & $33(16.33 \%)$ & $61(30.19 \%)$ & $1.49(1.16,1.92)$ & $1.80(1.27,2.26)$ & 0.001 \\
\hline Unwanted \& unplanned & $21(10.39 \%)$ & $28(13.86 \%)$ & $1.66(1.21,2.28)$ & $2.19(1.44,3.31)$ & 0.001 \\
\hline
\end{tabular}

study. While associations between fertility and overall rates of childhood malnutrition have been observed in numerous studies $[27,28]$ there has been less evidence of a relationship between the ability to plan pregnancy and women's ability to effectively care for children with MAM.

\section{Conclusions and Recommendations}

This study finds that, without intervention, the majority of children with MAM fail to recover. After a 2-month period, most either remain moderately malnourished or their condition deteriorates. Those from food-insecure households were more likely to have poor health outcomes than those from food secure households. These poor health outcomes are negatively associated with the duration of exclusive breastfeeding, minimum dietary diversity, maternal MUAC and whether pregnancies were planned and/or wanted. Based on the finding of the study the following recommendations were forwarded.

The high level of non-recovery found in our study suggests the need for ongoing, intensive, community-based nutrition education programs and nutritional surveillance to tackle the problem. It also suggests that children with MAM should be managed by targeted supplemental feeding programs, regardless of the food security status of the woreda. This would require the additional investment of scare resources. It could also be an important preventative measure that reduces the future outlay of resources for more expensive interventions to treat severe acute malnutrition and its co-morbidities. Our findings also suggest that it will be crucial to link these additional nutritional interventions for children with programs that provide intensive, high quality, prenatal and antenatal care for women. Our findings suggest that these programs should provide maternal nutritional support, counseling support for exclusive breastfeeding and diversifying childhood diets, and, most importantly, family planning counseling and provision of contraception, (particularly long-acting contraception), and safe abortion services when needed. This, in turn will require closer collaboration between stakeholders in reproductive health services, and those working in infant and young child feeding programs.

In order to inform the development of these programs, further study on the management of MAM should be conducted to explore risk factors not measured in the present study and to in particular, to address two of the main limitations on this study, its limited geographic scope, and its short time frame which did not include the pre-harvest and harvest seasons.

\section{Abbreviations}

AHR: Adjusted Hazard Rate; BMI: Body Mass Index; Cl: Confidence interval; CMAM: Comprehensive Moderate Acute Malnutrition; EBF: Exclusive breastfeeding; HEWs: Health Extension Workers; HFIAS: Household Food Insecurity Access Scale; MAM: Moderate Acute Malnutrition; MDD: Minimum Dietary Diversity; MUAC: Mid Upper-arm Circumference; NCHS: National Center for Health Statistics; SAM: Severe acute malnutrition; SD: Standard Deviation; SPSS: Statistical Package for Social Sciences; WFH: Weight for height; WFL: Weight for length; WHO: World Health Organization

\footnotetext{
Acknowledgments

The authors would like to thank the Debre Markos University, College of Medicine and Health Sciences for reviewing this paper. We also thank the Dangila Primary Hospital for their support in providing materials used in the project; the Fagita District for their help in printing materials; and the Fagita Health Center Director and staff for their support in survey development and data collection. The author's deep gratitude goes to the HEWs, participants, data collectors, and supervisors for their careful work in gathering information and collecting data for the study.
} 


\section{Funding}

This was a self-funded research project. There were no external organizations that funded this research.

\section{Availability of data and materials}

The datasets analyzed during the current study are available from the corresponding author upon reasonable request.

\section{Authors' contributions}

WA conceived and designed the study, performed analysis, and interpreted the data. DJ and MA assisted with the design, conception, analysis and interpretation of data. DJ also prepared and drafted the manuscript. SB assisted in drafting the manuscript. All authors read and approved the final manuscript.

\section{Ethics approval and consent to participate}

Ethical clearance was obtained from Ethical Review Committee of Debre Markos University's College of Medicine and Health Sciences. Letters of permission were also obtained from the Amhara Regional Health Bureau, the Awi Zonal Health Department, the Health Office of Fagita Lekoma District and its Kebele Administration Units. Verbal informed ascent was obtained from the parents of the child study subjects. The objectives of the study were explained to the parents who were assured that their names and the names of their children would be kept private. Privacy and confidentiality of collected information was ensured at all level. During the community-based nutritional screening phase of the study, we referred 5 children with severe acute malnutrition and 8 sick children referred to nearest health facilities. Health and nutritional education was given to all parents in the study.

\section{Consent for publication}

This manuscript does not report personal data such individual details, images or videos; therefore, consent for publication is not necessary.

\section{Competing interests}

The authors declare that they have no competing interests.

\section{Publisher's Note}

Springer Nature remains neutral with regard to jurisdictional claims in published maps and institutional affiliations.

\section{Author details}

${ }^{1} \mathrm{SCl}-\mathrm{MNCH}$, North Gondar, Ethiopia. ${ }^{2}$ Department of Public Health, College of Medicine and Health Science Debre Markos University, P.O. Box 269, Debre Markos, Ethiopia. ${ }^{3}$ Public Health Program, College of Education and Health Sciences, Touro University California, 1310 Club Drive, Mare Island Vallejo, CA 94592, USA.

\section{Received: 20 June 2017 Accepted: 13 December 2017}

Published online: 22 December 2017

\section{References}

1. Black RE, Victora CG, Walker SP, Bhutta ZA, Christian P, de Onis M, et al. Maternal and child undernutrition and overweight in low-income and middle-income countries. Lancet Lond Engl. 2013;382(9890):427-51.

2. Olofin I, McDonald CM, Ezzati M, Flaxman S, Black RE, Fawzi WW, et al. Associations of suboptimal growth with all-cause and cause-specific mortality in children under five years: a pooled analysis of ten prospective studies. PLoS One. 2013:8(5):e64636.

3. Nassar MF, Shaaban SY, Nassar JF, Younis NT, Abdel-Mobdy AE. Language skills and intelligence quotient of protein energy malnutrition survivors. J Trop Pediatr. 2012;58(3):226-30.

4. Ruel MT, Alderman $\mathrm{H}$. Nutrition-sensitive interventions and programmes: how can they help to accelerate progress in improving maternal and child nutrition? Lancet. 2013;382(9891):536-51.

5. Richard SA, Black RE, Gilman RH, Guerrant RL, Kang G, Lanata CF, et al. Wasting is associated with stunting in early childhood. J Nutr. 2012; 142(7):1291-6.

6. WHO, UNICEF, The World Bank: Joint child malnutrition estimates Levels and trends [Internet]. [cited 2017 Aug 29]. Accessed http://www. who.int/nutgrowthdb/estimates/en/
7. Rayhan MI, Khan MSH. Factors causing malnutrition among under five children in Bangladesh. Pak J Nutr. 2006:5(6):558-62

8. Semba RD. Nutrition and Development: A Historical Perspective. In: Nutrition and Health in Developing Countries [Internet]. Humana Press; 2008 [cited 2017 Aug 31]. p. 1-31. (Nutrition and Health Series). Accessed: https://link.springer.com/chapter/10.1007/978-1-59745-464-3_1

9. Central Statistical Agency-Ethiopia, ICF. Ethiopia Demographic and Health Sruvey 2016. Addis Ababa: CSA and ICF; 2017. [cited 2017 Aug 29]. Accessed: http://dhsprogram.com/publications/publication-FR328DHS-Final-Reports.cfm

10. Mucha N. Preventing Moderate Acute Malnutrition (MAM) through nutrition-sensitive interventions [Internet]. CMAM; 2014 [cited 2017 Aug 31]. (CMAM Forum Technical Brief). Accessed: http://files.ennonline.net/ attachments/2291/Nutrition-Sensitive-MAM-Prevention-CMAM-Forum-Dec2014.pdf

11. Dewey KG, Mayers DR. Early child growth: how do nutrition and infection interact? Matern Child Nutr. 2011;7(Suppl 3):129-42.

12. James P, Sadler K, Wondafrash M, Argaw A, Luo H, Geleta B, et al. Children with moderate acute malnutrition with no access to supplementary feeding Programmes experience high rates of deterioration and no improvement: results from a prospective cohort study in rural Ethiopia. PLoS One. 2016: 11(4):e0153530

13. Teshome B, Kogi-Makau W, Getahun Z, Taye G. Magnitude and determinants of stunting in children underfive years of age in food surplus region of Ethiopia: The case of West Gojam Zone. Ethiop J Health Dev. 2009;23:-2. [cited 2017 Aug 29] Available from: https://www.ajol.info/index. php/ejhd/article/view/53223

14. Mutisya M, Kandala N, Ngware MW, Kabiru CW. Household food (in)security and nutritional status of urban poor children aged 6 to 23 months in Kenya. BMC Public Health. 2015;15:1052.

15. Psaki S, Bhutta ZA, Ahmed T, Ahmed S, Bessong P, Islam M, et al. Household food access and child malnutrition: results from the eight-country MAL-ED study. Popul Health Metr. 2012;10:24.

16. Golden $\mathrm{MH}$. Proposed Recommended Nutrient Densities for Moderately Malnourished Children. Food Nutr Bull. 2009;30(3_suppl3):S267-342.

17. Larrea C, Kawachi I. Does economic inequality affect child malnutrition? The case of Ecuador. Soc Sci Med. 2005;60(1):165-78.

18. Trehan I, Banerjee S, Murray E, Ryan KN, Thakwalakwa C, Maleta KM, et al. Extending supplementary feeding for children under five with moderate acute malnutrition leads to lower relapse rates. J Pediatr Gastroenterol Nutr. 2015;60(4):544-9.

19. Fagita Lekoma District Health Office. Annual report of Fagita Lekoma District health office. Addis Kidam: Fagita Lekoma District health Office; 2013.

20. Dean A, Arner T, Sunki G, Friedman R, Lantinga M, Sangam S, et al. Epi Info ${ }^{\mathrm{TM}}$, a database and statistics program for public health professionals: CDC, Atlanta; 2011. [cited 2017 Aug 31]. Available from: https://wwwn. cdc.gov/epiinfo/user-guide/getting-started/Acknowledgements.html

21. Swindale A, Bilinsky P. Development of a universally applicable household food insecurity measurement tool: process, current status, and outstanding issues. J Nutr. 2006;136(5):1449S-52S.

22. Gebreyesus SH, Lunde T, Mariam DH, Woldehanna T, Lindtjørn B. Is the adapted household food insecurity access scale (HFIAS) developed internationally to measure food insecurity valid in urban and rural households of Ethiopia? BMC Nutr. 2015;1:2.

23. WHO Multicentre Gwrowth. Reference study group. WHO child growth standards based on length/height, weight and age. Acta Paediatr Suppl. 2006:450:76-85.

24. IBM Corp. IBM SPSS statistics for windows, version 20.0. IBM Corp: Armonk; 2011

25. Eshete $H$, Abebe $Y$, Loha E, Gebru T, Tesheme T. Nutritional status and effect of maternal employment among children aged 6-59 months in Wolayta Sodo town, southern Ethiopia: a cross-sectional study. Ethiop J Health Sci. 2017;27(2):155-62

26. FAO, IFAD, WFP. The state of food insecurity in the world 2013. Rome: FAO; 2013. [cited 2017 Aug 29]. Accessed: http://www.fao.org/docrep/018/ i3434e/i3434e00.htm

27. Asfaw M, Wondaferash M, Taha M, Dube L. Prevalence of undernutrition and associated factors among children aged between six to fifty nine months in Bule Hora district, South Ethiopia. BMC Public Health. 2015;31:15. [cited 2017 Aug 26]Accessed: http://www.ncbi.nlm.nih.gov/pmc/articles/ PMC4314803/ 
28. Lalou R, Mbacke C. The micro-consequences of high fertility on child malnutrition in Mali. In: Fertility, family size, and structure: consequences for families and children, vol. 232. New York: Population Council; 1993. p. 193. (Proceedings of a Population Council Seminar). Accessed: https://www. popline.org/node/336714.

Submit your next manuscript to BioMed Central and we will help you at every step:

- We accept pre-submission inquiries

- Our selector tool helps you to find the most relevant journal

- We provide round the clock customer support

- Convenient online submission

- Thorough peer review

- Inclusion in PubMed and all major indexing services

- Maximum visibility for your research

Submit your manuscript at www.biomedcentral.com/submit 